NBER WORKING PAPER SERIES

\title{
REAL EXCHANGE RATE FLUCTUATIONS AND THE DYNAMICS OF RETAIL TRADE INDUSTRIES ON THE U.S.-CANADA BORDER
}

\author{
Jeffrey R. Campbell \\ Beverly Lapham \\ Working Paper 8558 \\ http://www.nber.org/papers/w8558 \\ NATIONAL BUREAU OF ECONOMIC RESEARCH \\ 1050 Massachusetts Avenue \\ Cambridge, MA 02138 \\ October 2001
}

We thank Martin Boileau, Lars Hansen, Allen Head, Chad Syverson, and Oved Yosha for helpful comments on previous versions of this paper. The National Science Foundation supported Campbell's research through grant SBR-9730442, "Business Cycles and Industry Dynamics." The Social Science and Humanities Research Council of Canada supported Lapham's research. Emin Dinlersoz provided expert research assistance at an early stage of this project. The latest versions of this paper and its technical appendix are available on the World Wide Web at http://home.uchicago.edu/ jcampbe. Please direct correspondence to Campbell at Department of Economics, University of Chicago, 1126 East 59th Street, Chicago, Illinois 60637. The views expressed herein are those of the authors and not necessarily those of the National Bureau of Economic Research.

(C) 2001 by Jeffrey R. Campbell and Beverly Lapham. All rights reserved. Short sections of text, not to exceed two paragraphs, may be quoted without explicit permission provided that full credit, including (C) notice, is given to the source. 
Real Exchange Rate Fluctuations and the Dynamics of Retail Trade Industries on the U.S.-Canada Border

Jeffrey R. Campbell and Beverly Lapham

NBER Working Paper No. 8558

October 2001

JEL No. F4, E3, L8

\section{ABSTRACT}

Consumers living near the U.S.-Canada border can shift their expenditures between the two countries, so real exchange rate fluctuations can act as demand shocks to border areas' retail trade industries. Using annual county-level data, we estimate the effects of real exchange rates on the number of establishments and their average payroll in border counties for four retail industries. In three of the four industries we consider, the number of operating establishments responds either contemporaneously or with a lag of one year to real exchange rate movements. For these industries, the response of retailers' average size is less pronounced. The rapid response of net entry is inconsistent with any model of persistent deviations from purchasing power parity that depends on retailers' costs of changing nominal prices.

Jeffrey R. Campbell

Department of Economics

University of Chicago

1126 East 59th Street

Chicago, IL 60637

and NBER

jcampbe@midway.uchicago.edu
Beverly Lapham

Department of Economics

Queen's University

Dunning Hall

Kingston, ON K7L 3N6

Canada

laphamb@qed.econ.queensu.ca 
This paper estimates the effects of real exchange rate fluctuations on the number of stores and their average payroll in retail trade industries located near the U.S.-Canada border. Our empirical results address two basic questions concerning retailers' short-run and long-run responses to shocks: How important is retailers' price stickiness for propagating nominal shocks? How quickly does net entry respond to demand shocks? The answers to these questions are related because it should take less time for an incumbent retailer to change nominal prices than it does for a potential entrant to open a store. Macroeconomic models featuring sticky nominal prices, such as Chari, Kehoe, and McGrattan's (2000a) and Christiano, Eichenbaum, and Evans' (2001), embody this assumption by fixing the number of producers over the relevant horizon. In these models, an industry that expands because nominal disturbances erode the real value of fixed nominal prices displays increasing average producer size and no increase in the number of producers. However, we find the opposite to be true for two of the industries we examine that are known to display infrequent store-level nominal price adjustments, Food Stores and Eating Places. For those industries, fluctuations in the real exchange rate induce a change in the number of stores either contemporaneously or with a lag of one year. Since the typical half-life of a deviation of the real exchange rate from purchasing power parity is between three and four years, our results imply that retail-level price stickiness cannot be primarily responsible for these observed international price differences.

For retailers in border communities, real exchange rate fluctuations represent changes in the price of a substitute good. Thus, they have effects similar to an ordinary demand shock. Figure 1 illustrates these effects. Its top panel depicts the Canada-U.S. real exchange rate between 1972 and 1998 (normalized to equal 1 in 1972), and its bottom two panels each plot a measure of cross-border shoppers, the number of one-day trips by Canadians and Americans to the other country. The strong Canadian dollar in the late 1980's and early 1990's induced a surge in the number of Canadian trips to the U.S. This reversed itself in the middle of the 1990's when the Canadian dollar depreciated and American trips to Canada 
dramatically increased. The spike in American trips in 1980-1981 came at a time when the Canadian National Energy Policy greatly reduced gasoline's price in Canada relative to its U.S. price. In response, American consumers' living near the border shifted their gasoline expenditures towards Canadian retailers.

We consider four industries for which travel costs relative to the value of a typical purchase make ongoing international arbitrage impractical for consumers living very far away from the U.S.-Canada border: Food Stores, Gasoline Service Stations, Eating Places, and Drinking Places. For each of these industries, we estimate a panel-data vector autoregression using annual county-level data on the number of retail establishments and their average annual payroll from the ten contiguous states that border Canada. As explanatory variables, we include current and lagged real exchange rates interacted with a measure of each county's sensitivity to real exchange rate fluctuations, derived from the model we consider in Section I. Since the real exchange rate is an endogenous variable, determined by structural shocks that can have direct effects on consumers' purchasing decisions and retailers' costs, we use observations from counties off of the U.S.-Canada border to estimate coefficients on time dummies that control for these direct effects. In this way, we use variation in counties' proximity to the border to identify the expenditure-shifting effects of real exchange rates on border counties' retail trade industries. In all of the industries we study, we find that these effects are significant.

The rest of this paper is organized as follows. In the next section, we present a model of retail industry dynamics with cross-border shopping. Section II describes the model's empirical specification, the data, and the GMM estimation procedure we use. Section III presents the estimation results, and Section IV discusses the relationship of our work with the relevant literature from international macroeconomics and industrial organization. Section V contains concluding remarks regarding our results' implications for future research. 


\section{A Cross-Border Shopping Model}

To structure our empirical analysis, we develop a model of retail industry dynamics with cross-border shopping. If neither retailers' prices nor their entry decisions can respond to the shocks driving real exchange rate fluctuations, then these shocks' expenditure-shifting effects can only change average store size and not the number of stores. The empirical predictions of such a sticky-price model are already clear, so we incorporate into our model the opposite assumptions of flexible retail price setting and free entry. We also describe below the implications of combining these two models by assuming that some retailers' nominal prices are sticky while the prices and entry decisions of others can respond to all relevant disturbances.

We use a partial equilibrium model of two counties: $U$ located in the United States and $C$ located directly across the border in Canada. Each county has a retail-trade sector that produces differentiated goods in a monopolistically-competitive market with free entry. Retailers in both counties face no price rigidities and use identical constant-percentage markup pricing rules, so deviations from PPP entirely reflect differences in retailers' marginal costs. Our model is a partial equilibrium model because we assume that the marginal costs of retailers in $U$ and $C$ are determined in their respective national economies. Retailers' cost differences could arise from differences in retail technology, regulations which prevent arbitrage in wholesale goods, nominal rigidities in manufacturers' and wholesalers' prices, or some combination of these sources. Because consumers in border counties can choose where to shop, deviations from PPP induce a shift of expenditures towards the less expensive county. We analyze the response of both counties' retail-trade industries to movements in relative costs, focusing on the behavior of variables we observe in our data, the number of establishments and their average payroll in the U.S. county. 


\section{A Consumers}

There are $S_{j}$ consumers in county $j$ and a fraction, $\lambda$, of those consumers are travellers who purchase from both domestic and foreign retailers. The remaining consumers in a county can only purchase from domestic retailers and are referred to as non-travellers. Consumers have the following preferences:

$$
U=d^{1-\gamma}\left(\int_{0}^{N_{U}} x_{i U}^{\nu} d i+\int_{0}^{N_{C}} x_{i C}^{\nu} d i\right)^{\frac{\gamma}{\nu}}
$$

where $d$ is consumption of a homogeneous numeraire good and $x_{i j}$ is consumption of differentiated good $i$ sold in county $j \in\{U, C\}$, and both $\gamma$ and $\nu$ are strictly between zero and one. For non-travellers, consumption of goods sold by foreign retailers equals zero. The number of distinct goods offered for sale in county $j$ is $N_{j}$ and is determined in equilibrium. All consumers are endowed with $\omega$ units of the numeraire good which they use to finance consumption expenditures.

\section{B Technology}

Each retailer incurs a fixed cost of $\phi$ units of the numeraire good in each period. She also uses labor and materials to produce her single distinct good using a technology with constant marginal cost $c_{j}, j=U, C$. The fractions of variable and fixed costs paid to labor are $\alpha$ and $\delta$, so the payroll of a retailer located in county $j$ with output equal to $x$ is

$$
W_{j}=\alpha c_{j} x+\delta \phi
$$

\section{Free-Entry Equilibrium}

The retail production technology is available to large pools of potential entrants in both countries. The marginal costs, $c_{U}$ and $c_{C}$, are random variables that are exogenous from the perspective of a single county's retail sector. After observing $c_{U}$ and $c_{C}$, potential entrants simultaneously decide whether or not to irreversibly incur the fixed cost and produce. In 
equilibrium those that enter choose their prices to maximize profits, and further entry is not profitable in either location. For simplicity, we suppose retailers must incur the fixed cost every period, so a border county's retail-trade sector is characterized by the infinite repetition of this free-entry game. ${ }^{1}$

The isoelasticity of consumers' Marshallian demand curves implies that producers' profit maximizing prices will follow the familiar constant-percentage markup over marginal cost rule:

$$
p_{j}=\frac{c_{j}}{\nu},
$$

where $p_{j}$ is the price chosen by all retailers in county $j$. Combining this with the zero profit condition and (1) yields each retailer's equilibrium output, $x_{j}$, and one of our observable variables, average payroll.

$$
\begin{aligned}
x_{j} & =\frac{\phi \nu}{c_{j}(1-\nu)} \\
W_{j} & =\frac{\alpha \phi \nu}{1-\nu}+\delta \phi .
\end{aligned}
$$

Retailers' average sizes in both counties (measured with either sales, $p_{j} \times x_{j}$ or payroll, $W_{j}$ ) are constant, so all of the industry's response to fluctuations in $c_{U}$ and $c_{C}$ must occur through changes in the number of retailers on both sides of the border.

To determine $N_{U}$ and $N_{C}$, we equate the output per retailer that is consistent with freeentry from (3) with the output demanded by consumers at the prices given by (2). Doing so yields

$$
\begin{aligned}
& \frac{(1-\lambda) S_{U}}{N_{U}}+\frac{\lambda\left(S_{U}+S_{C}\right)}{N_{U}+N_{C} r^{\nu /(\nu-1)}}=\frac{\phi}{\gamma \omega(1-\nu)} \\
& \frac{(1-\lambda) S_{C}}{N_{C}}+\frac{\lambda\left(S_{U}+S_{C}\right)}{N_{U} r^{\nu /(1-\nu)}+N_{C}}=\frac{\phi}{\gamma \omega(1-\nu)},
\end{aligned}
$$

where $r \equiv\left(p_{C} / p_{U}\right)$, which we henceforth refer to as the industry real exchange rate.

\footnotetext{
${ }^{1}$ With minor modifications, our analysis carries through if we instead assume that $\phi$ is a sunk cost of entry and that incumbent establishments each face a constant probability of exogenous destruction.
} 
If there were no cross-border shopping, then $\lambda=0$ and finding the values of $N_{U}$ and $N_{C}$ that satisfy (5) and (6) is straightforward. If $r=1$ and $\lambda>0$, then these equations have the same solution as they do when $\lambda=0$ :

$$
\bar{N}_{j}=S_{j} \frac{\gamma \omega(1-\nu)}{\phi}, j \in\{U, C\}
$$

That is, if the marginal costs in the two counties equal each other, the retail trade sector in a border county should be no different from its counterpart in an interior county.

To determine the responses of $N_{U}$ and $N_{C}$ to changes in $r$, take a log-linear approximation of (5) and (6) around the point $r=1, \bar{N}_{U}, \bar{N}_{C}$. Solving the resulting equations yields

$$
\begin{aligned}
& \ln \left(N_{U} / \bar{N}_{U}\right)=\left[\frac{\nu \lambda}{(1-\nu)(1-\lambda)}\right]\left[\frac{S_{C}}{S_{U}+S_{C}}\right] \ln (r) \\
& \ln \left(N_{C} / \bar{N}_{C}\right)=\left[\frac{-\nu \lambda}{(1-\nu)(1-\lambda)}\right]\left[\frac{S_{U}}{S_{U}+S_{C}}\right] \ln (r)
\end{aligned}
$$

When a decrease in $c_{U}$ causes $r$ to increase, the number of producers operating in county $U$ rises. Simultaneously, the number of producers in county $C$ falls.

Because $S_{U}$ and $S_{C}$ vary across U.S. border counties, so will the second term in brackets in (8). We refer to this term as the (U.S.) county's sensitivity measure. As intuition suggests, it is increasing in the population of Canadian consumers and decreasing in the population of U.S. consumers. The sensitivity measure is an important component of our estimation. ${ }^{2}$

\section{Retail Industry Dynamics with Sticky Prices}

Thus far, we have presumed that a stable industry structure is a prerequisite for price stickiness of a meaningful duration. Nevertheless, both massive ongoing restructuring of retail trade industries and infrequent nominal retail price changes have been independently

\footnotetext{
${ }^{2}$ If we suppose that retailers' entry decisions must be made before observing $r, W_{U}$ and $W_{C}$ will also fluctuate when $\ln r$ differs from its expectation at the time of entry, and $N_{U}$ and $N_{C}$ will depend on past values of $\ln r$. The elasticities of $W_{U}$ and $N_{U}$ with respect to $r$ and its past values are both proportional to the sensitivity measure in (8), so the empirical approach we derive in Section II remains valid.
} 
documented. ${ }^{3}$ For this reason, it may seem desirable to incorporate ongoing restructuring into a model with sticky prices. In this vein, we have extended our model to include U.S. and Canadian currencies and retailers in both counties that are "sticky." This paper's technical appendix describes this extension in detail. Sticky retailers' entry and nominal pricing decisions must be made before any shock's realization, while the "flexible" retailers we have focused on above continue to have complete information for both of these choices. In this environment, a nominal shock that lowers the real prices of sticky retailers in $C$ but does not change the relative real marginal costs between $C$ and $U$ induces a reduction in the number of flexible retailers in $C$. The reduction in entry exactly offsets the effects of sticky retailers' price inflexibility, so that the correctly constructed aggregate price index for $C$ (which accounts for the change in variety) changes one for one with the nominal disturbance. The real exchange rate is unchanged, so the Canadian nominal disturbance has no expenditure shifting effects and no effects on the retail industry in $U$. This result demonstrates that price stickiness and nominal shocks can generate expenditure shifting between $U$ and $C$ only if it takes longer to implement an entry decision than it does to change a nominal price. ${ }^{4}$

\section{Data and Estimation}

The empirical model that we use for estimation is an extension of the model considered above that accounts for county-specific and economy-wide disturbances to cost and demand as well as unobserved heterogeneity across counties. The estimating equation uses the sensitivity measure from (8), but it does not restrict real exchange rates to impact only the number of

\footnotetext{
${ }^{3}$ See Foster, Haltiwanger, and Krizan (2001) for measurement of entry and exit in U.S. retail industries, Lach and Tsiddon (1996) for evidence of infrequent price adjustment in Israeli food stores, and MacDonald and Aaronson (2000) for similar evidence in U.S. Eating Places.

${ }^{4}$ Including sticky retailers hardly alters the model's predictions regarding changes in the relative real marginal costs of retailers in $U$ and $C$. In particular, the sensitivity measure in (8) remains appropriate.
} 
retailers. Instead, it allows both the number of retailers and their average payroll to respond to real exchange rates. This section explains the empirical model, describes the data we use, and summarizes our GMM estimation procedure. We begin with the empirical model.

\section{A The Empirical Model}

We estimate our model separately for the four industries we consider. For each year and each county in our sample we observe the number of establishments operating in the industry and the U.S. dollar value of industry payroll. We also observe each county's population in 1990. For the industry of interest in county $i$, we define the vector

$$
y_{i t}=\left[\begin{array}{ll}
\ln N_{i t} & \ln W_{i t}
\end{array}\right]^{\prime},
$$

where $N_{i t}$ is the number of stores operating at any time during the year divided by the 1990 population of county $i$ (establishments), and $W_{i t}$ is the dollar value of industry payroll for the year divided by the number of establishments (average payroll). Our data set provides annual observations of $y_{i t}$.

The estimating equation we use is

$$
y_{i t}=\alpha_{i}+\mu_{t}+\Lambda y_{i t-1}+\beta^{\prime}\left(s_{i} \times e_{t}\right)+\varepsilon_{i t}
$$

where $\alpha_{i}$ is a random county-specific intercept, $\mu_{t}$ is a time-specific effect common to all counties, $\Lambda$ and $\beta$ are $(2 \times 2)$ matrices of unknown coefficients,

$$
\begin{aligned}
e_{t} & =\left[\begin{array}{ll}
\ln r_{t} & \ln r_{t-1}
\end{array}\right]^{\prime}, \\
s_{i} & =\frac{S_{i C}}{S_{i U}+S_{i C}},
\end{aligned}
$$

and $\varepsilon_{i t}$ is a disturbance term. ${ }^{5}$ In (12), $S_{i U}$ is the population of U.S. county $i$ and $S_{i C}$ is a

\footnotetext{
${ }^{5}$ The fixed effects in (10) allow us to use unscaled observations on the number of establishments rather than the per capita measure we use. We chose the latter specification, however, because the GMM estimation procedure described below treats $\alpha_{i}$ as a component of the model's error rather than as a parameter to be estimated. Scaling establishments by population as the model suggests reduces the overall error variance.
} 
measure of population in its Canadian counterpart. If county $i$ does not share a border with Canada, then we set $S_{i C}=0$.

Consider first the implications of (10) for counties that do not border Canada, which we henceforth refer to as interior counties. In this case $s_{i}=0$, and (10) implies that $y_{i t}$ follows a first-order vector autoregression (VAR) with intercept $\alpha_{i}$ and disturbance term $\mu_{t}+\varepsilon_{i t}$. We assume that the roots of $|I-\Lambda L|$ lie outside of the unit circle and that if the county is interior, then

$$
\begin{aligned}
\mathbf{E}\left[\varepsilon_{i t}\right] & =0, \\
\mathbf{E}\left[\varepsilon_{i t} \varepsilon_{i \tau}\right] & =0 \text { if } t \neq \tau,
\end{aligned}
$$

That is, for an interior county $\varepsilon_{i t}$ is the fundamental error (in the sense of the Wold decomposition theorem) for $y_{i t}-(I-\Lambda L)^{-1} \mu_{t}$. We furthermore assume that for interior counties

$$
\mathbf{E}\left[\alpha_{i}\right]=0
$$

Given the presence of $\mu_{t}$ in (10), this is only a normalization.

This specification for interior counties' fluctuations can be derived from our model if we suppose that each consumer's income $(\omega)$ and each retailer's fixed cost $(\phi)$ are subject to county-specific disturbances that themselves follow a first-order VAR in logarithms. Under this interpretation, the intercept term $\alpha_{i}$ reflects these variables' county-specific means. The disturbance term's common component, $\mu_{t}$, embodies aggregate disturbances that effect all counties uniformly. The economy-wide effects of any structural aggregate shock that causes the real exchange rate to fluctuate will be incorporated into $\mu_{t}$. There are no constraints on $\mu_{t}$, and we treat it as a parameter to be estimated.

To characterize the fluctuations in $y_{i t}$ for border counties, we assume that their responses to the aggregate disturbances in $\mu_{t}$ are identical to the responses of interior counties and that the same autoregressive equation describes their dynamics in the absence of real exchange rate fluctuations. For border counties the current and lagged real exchange rates interacted 
with $s_{i}$ are added to (10) as explanatory variables. ${ }^{6}$ We include the lagged real exchange rate to allow the effects of a completely transitory disturbance to $\ln r_{t}$ to be equally short-lived, as they are in the (essentially static) model.

The real exchange rate between each U.S. border county and its Canadian counterpart potentially varies across counties. Let $r_{i t}$ denote the relative retail price between county $i$ and its Canadian counterpart. The location-specific price data needed to construct $r_{i t}$ are not available to us, so instead (10) uses its national-level analogue, $r_{t}$. We further discuss our measure of $r_{t}$ in Section $\mathrm{C}$ below. To replace $r_{i t}$ with $r_{t}$ in the model, we suppose that the linear projection of $r_{i t}$ on $r_{t}$ has a slope coefficient of one for each border county. That is

$$
\ln r_{i t}=a_{i}+\ln r_{t}+\zeta_{i t}
$$

where $\left\{\zeta_{i t}\right\}$ is a mean-zero covariance-stationary stochastic process that is independent across counties. ${ }^{7}$

The difference between $r_{i t}$ and $r_{t}$ implies that the interpretations we have placed on $\varepsilon_{i t}$ and $\alpha_{i}$ for interior counties are inappropriate. Instead, $\varepsilon_{i t}$ now equals the the model's true error plus a measurement error term involving $\zeta_{i t}$ and $\zeta_{i t-1}$, and $\alpha_{i}$ equals the true intercept plus a term involving $a_{i}$. The presence of measurement error implies that (13) also applies to $\varepsilon_{i t}$ for a border county, but (14) and (15) do not. The moment conditions we use to identify the model's parameters account for these differences between interior and border counties' observations.

We now turn to the discussion of our observations of $y_{i t}, r_{t}$, and $s_{i}$.

\footnotetext{
${ }^{6}$ Note that we do not include the relative per capita consumption expenditures of U.S. and Canadian consumers in (10). Although we assumed in Section I that consumers in counties $U$ and $C$ had the same real consumption expenditures, this was only a simplification. Variation in relative per capita consumption between $U$ and $C$ has no equilibrium impact on the retail industry in $U$, so its omission from (10) is not a misspecification.

${ }^{7}$ Equation (10) is also correct if instead the slope coefficient in (16) equals $b \neq 1$, but the interpretation of $\beta$ must be suitably altered to reflect the change in scale.
} 


\section{B Observations of Retail Trade Industries}

Our observations of retail trade industries come from the United States Census' annual publication, County Business Patterns $(C B P)$. We construct our data set from twenty years of this publication from 1977 through 1996. We focus on counties in the ten contiguous states that border Canada because we wish the sample's interior counties to be as otherwise similar as possible to the border counties. For each retail trade industry, the $C B P$ reports each county's annual payroll and the number of establishments with employees, among other variables. Because this data is based on administrative payroll tax records, its quality is very high. Our empirical work uses the establishment count divided by the county's population in 1990 for $N_{i t}$ and uses annual payroll divided by the number of establishments for $W_{i t}$.

Our discussion above has presumed that only those counties that share a border with Canada are exposed to cross-border shopping. For some retail trade industries, this is clearly not the case. For example, Ford (1992) surveyed Canadian consumers in Toronto, Hamilton, and the Niagara-St. Catherines region regarding their shopping destinations in the U.S. Many consumers reported shopping outside of the New York border counties of Erie and Niagara, particularly if the shopping trips were for durable goods such as furniture and electronics. Conversely, U.S. consumers from counties without a Canadian border can shop in Canada if they are willing to travel. However, Ford's (1992) survey data indicates that purchasers of food and gasoline, the two most frequently purchased items by cross-border shoppers, tended to shop very near the border. For this reason, we restrict our analysis to retail trade industries that Ford's (1992) data and our own experience as cross-border

shoppers indicate consumers are unwilling to travel far to purchase. The industries we consider are Food Stores (SIC 54), Gasoline Service Stations (SIC 554), Eating Places (SIC 5812), and Drinking Places (SIC 5813).

Our data set is incomplete because the Census withholds the payroll information for any county-industry observation where that datum may disclose information about any individual producer. The Census does not reveal how it determines which observations must be 
withheld, but these disclosure cases tend to occur in counties with small populations and few establishments. To produce a balanced panel of payroll observations across counties, we use data in the $C B P$ on each state's annual payroll and the number of establishments by employment size class to forecast and replace the withheld payroll observations. This paper's technical appendix describes this data replacement procedure in greater detail.

Our model economy describes competition between a large number of producers, so it is unrealistic to expect it to describe retail industry dynamics in very small counties. For this reason, we confine our analysis to counties with relatively large numbers of establishments using two selection criteria. First, we consider counties with populations greater than 20,000 people, as measured in the 1990 decennial census. There are 256 such counties in the ten contiguous border states, and nineteen of these counties share a border with Canada. Second, we drop all observations from any county-industry pair with ten or more observations withheld by the Census Bureau. This criterion lessens the dependence of our results on our data replacement procedure. For the resulting sample of counties, $1.2 \%$ of our county-industry-year observations have imputed payroll data. As noted above, disclosure withholding primarily affects counties with few producers, so our resulting sample is of relatively unconcentrated industries in relatively populated counties.

Our county selection criteria produce different samples for each industry we consider. Table 1 provides summary statistics for each industry's sample of counties. ${ }^{8}$ Its first column reports the number of counties included in each sample, and its remaining three columns report the first quartile, median, and third quartile, across counties, of the average number of establishments, across years, serving that industry. None of the 256 counties with populations greater than 20,000 had their payroll observations withheld for ten or more years in Food Stores or Gasoline Service Stations. Our disclosure criterion eliminates 11 counties for Eating Places and 21 counties for Drinking Places. For each of these industries, five of the

\footnotetext{
${ }^{8}$ The statistics in Table 1 use the raw establishment counts from the $C B P$. These have not been scaled by the county's 1990 population.
} 
eliminated counties are border counties. The first sample quartiles of average establishment counts indicate the extent to which our selection procedures leave relatively unconcentrated industries. With the exception of Drinking Places, the first quartiles of the average establishment counts are all above 15. For drinking places, the first quartile is 11.8. It appears that our county selection procedure produced a sample of relatively unconcentrated industries.

To assess how variations in the number of establishments and their average payroll each contribute to retail trade industries' county-specific fluctuations, we regressed each of these variables' logarithms against a set of time dummies. We then tabulated the sample standard deviations of that regression's residuals for each county. Table 2 reports the medians, across counties, of these standard deviations for each retail trade industry. In practice, these medians are close to their corresponding means. Relative to many aggregate time series, these median standard deviations are quite high. The lowest are in Eating Places, 0.09 for establishments and 0.10 for average payroll. Drinking Places has the highest median standard deviations, 0.17 and 0.22 respectively. Overall, establishments' median standard deviations are not much lower than those of average payroll, indicating that these industries' structures are far from rigid.

\section{International Relative Prices}

Our measures of international relative prices are based on national price indices from the United States and Canada for specific goods and the exchange rate between the two countries' currencies. For each retail trade industry, we found matching consumer price indices for the goods for sale by that industry from the two countries. ${ }^{9}$ We construct the industry-specific real exchange rate by taking the ratio of the relevant Canadian price index to the relevant U.S. price index multiplied by the nominal exchange rate. Hence, an increase in the real exchange rate reflects an depreciation from the U.S. perspective. Table 3 lists the U.S. and Canadian CPI series used to construct the relative price series for each of the four industries

\footnotetext{
${ }^{9}$ For Drinking Places, relative price data is not available until the third year of our sample.
} 
we consider.

The first two columns of Table 4 report the sample standard deviation and first autocorrelation for the industries' relative price series, expressed in logarithms. For all of the industries but Service Stations, the standard deviations of the relative price series are all between 0.07 and 0.09. The standard deviation of the relative price of Gasoline is much higher than this, 0.21. Most of this variance reflects fluctuations in the years of the Canadian National Energy Policy (NEP). In response to international oil price shocks in the 1970's, the Canadian federal government implemented the NEP which, among other things, imposed import subsidies and export taxes on petroleum products. Thus while gasoline prices rose considerably in the U.S. in response to these shocks, Canadian gasoline prices did not and the relative price of gasoline between the two countries exhibited considerable fluctuation.

Unsurprisingly, the relative price series are all highly persistent, with first order autocorrelations between 0.75 and 0.88 . Table 4's final column reports the contemporaneous correlation between each industry's relative price series and that constructed with the aggregate CPI's for all goods less energy. The relative prices for Eating Places and Drinking Places are both highly correlated with this aggregate real exchange rate. The relative prices of food purchased at stores and gasoline have somewhat lower correlations.

\section{Sensitivity Measures}

Our model predicts that the elasticity of retail trade activity on the U.S. side of the border with respect to the real exchange rate depends on the share of the border area's consumers that are Canadian, $s_{i}$. Consumers' strong preferences for product diversity directly produce this result, but it accords well with the intuition that being located next to Canadian land is irrelevant for a border county's retail industry if there are no nearby Canadians.

To measure $S_{i U}$, we use data on each county's population in the 1990 decennial census. Measuring $S_{i C}$ is less straightforward, because there is no natural or political geographic partition of Canada that indicates which Canadians are potential cross-border shoppers. It 
is possible to measure $S_{i C}$ as the number of Canadians living within a particular distance of county $i$, however this measure of $S_{i C}$ is unsatisfactory because it does not account for potential geographic obstacles to travelling between county $i$ and these Canadians' homes and shops. For instance, travel bottlenecks such as bridges may make even a short distance costly to travel, while an adequate highway leading to the border may make such trips very convenient.

Our preferred measure of $S_{i C}$ uses observations of the number of Canadians who cross the international border into county $i$ to estimate the number of Canadians who are potential cross-border shoppers. Using interview data from border crossing points, Statistics Canada tabulates the number of U.S. and Canadian travellers that travel through each official border crossing point while either embarking upon or returning from a trip lasting one-day or less to the other country. Statistics Canada does not keep track of travellers' identities, so an individual making multiple trips to or from Canada in a year will contribute to the count of travellers on each trip. This data is available from 1990 through 1999. We average the data across these years to measure the average number of U.S. and Canadian travellers for county $i$, which we denote with $T_{i U}$ and $T_{i C}$.

Our model implies that the number of Canadians crossing the border on one-day trips is $\lambda S_{i C}$, but it implies nothing about the frequency of cross-border shopping during one year for a travelling consumer. To construct a measure of $S_{i C}$ based on $T_{i C}$, we assume that the average number of trips taken by a travelling consumer, $\theta$, is constant across locations. Given values of $\lambda$ and $\theta$, we can then measure $S_{i C}$ with $T_{i C} /(\lambda \theta)$. The resulting measure of county $i$ 's exposure to cross-border shopping is

$$
s_{i}=\frac{T_{i C}}{\lambda \theta S_{i U}+T_{i C}} .
$$

As this expression for $s_{i}$ makes clear, the problem of choosing $\lambda \theta$ is one of expressing county $i$ 's population in units of travellers. For our baseline measure of $s_{i}$, we assume that all U.S. travellers entering Canada for one-day trips from county $i$ are residents in that county, and use the average of $T_{i U} / S_{i U}$ across border counties to measure $\lambda \theta$. The resulting value of 
$\lambda \theta$ is 7.49. Across the nineteen border counties, the average and standard deviation of this baseline measure of $s_{i}$ are 0.60 and 0.27 . In Section III we examine the implications using other measures of $s_{i}$.

\section{E GMM Estimation}

The estimation of panel-data vector autoregressions similar to (10) without the explanatory variables $s_{i} \times e_{t}$ is a well-studied problem. To estimate (10), we use a GMM estimator based on Blundell and Bond (1998), which uses moment conditions derived from the lack of serialcorrelation in $\varepsilon_{i t}$ and an assumption that $y_{i t}$ is mean-stationary. A novel complication that

arises in our analysis is the presence of the measurement error due to the replacement of $\ln r_{i t}$ with $\ln r_{t}$. We have placed no restrictions on the serial correlation properties of $\zeta_{i t}$, so this measurement error's presence invalidates Blundell and Bond's (1998) moment conditions when applied to observations from border counties. However, $s_{i}$ equals zero for the majority of our sample counties, so their moment conditions remain valid if we impose them only on observations from counties without a Canadian border. The appropriately modified moment conditions which we use in our GMM estimator are

$$
\begin{aligned}
\mathbf{E}\left[I\left\{s_{i}=0\right\} \Delta \varepsilon_{i t} y_{i t-s}\right] & =0, t=3, \ldots, T, t>s \geq 2, \\
\mathbf{E}\left[I\left\{s_{i}=0\right\}\left(\alpha_{i}+\varepsilon_{i t}\right) \Delta y_{i t-1}\right] & =0, t=3, \ldots, T . \\
\mathbf{E}\left[I\left\{s_{i}=0\right\}\left(\alpha_{i}+\varepsilon_{i t}\right)\right] & =0, t=2, \ldots, T
\end{aligned}
$$

Taken together, the moment conditions in (18), (19), and (20) are more than sufficient for identifying and estimating the 4 autoregressive parameters and the $2(T-1)$ year-specific intercepts for $T=20$. However, these conditions clearly leave $\beta$ unidentified. Because (13) applies to border counties, it must be the case that

$$
\mathbf{E}\left[\Delta \varepsilon_{i t} s_{i}\right]=0, t=3, \ldots, T .
$$


These $2(T-2)$ moment conditions identify $\beta .^{10}$ The GMM estimator we use is based on the moment conditions in (18), (19), (20), and (21).

We use a one-step GMM estimator, in which the weighing matrix is a version of that used by Blundell and Bond (1998) appropriately modified to account for the additional moment conditions in (20), and (21). The technical appendix describes the estimation procedure in more detail.

\section{Estimation Results}

Our baseline empirical analysis for the four industries we consider produces estimates of eight autoregressive equations' parameters. To conserve space, we report complete results for one industry, Food Stores, as an example. For the remaining industries, we report the estimates of the coefficients on current and lagged relative prices and summarize our estimates of the autoregressive coefficients.

\section{A Food Stores}

Table 5 presents the GMM estimates of the coefficients of interest in (10) for Food Stores. Before estimation, we divided $s_{i}$ by its mean value, so that the coefficients on current and lagged relative prices can be interpreted as elasticities at a county with the mean value of $s_{i}, 0.60$. Below each estimate is its heteroskedasticity-consistent standard error. The Table's final row reports the value of a Wald test of the null-hypothesis that the international relative prices can be excluded from that equation. These tests are asymptotically distributed as $\chi^{2}$ random variables with two degrees of freedom.

The estimates in Table 5 indicate that in the Food Stores industry, the number of establishments responds to movements in the relative price of food purchased from stores after one

\footnotetext{
${ }^{10}$ Note that because the mean of $a_{i}$ may be non-zero we cannot claim that $\mathbf{E}\left[\alpha_{i} s_{i}\right]=0$ for border counties, which would be necessary for adding the moment condition $\mathbf{E}\left[\left(\alpha_{i}+\varepsilon_{i 2}\right) s_{i}\right]=0$.
} 
year. In particular, in the establishments equation, $\widehat{\beta}_{0}$ equals -.071 and is not statistically significant while the estimate for the coefficient on the lagged real exchange rate, $\widehat{\beta}_{1}$, equals 0.151. This has the sign predicted by our model and is statistically significant at the $5 \%$ level. The Wald exclusion test statistic for the establishments equation equals 4.98, which is significant at the $10 \%$ level. The point estimates of $\beta_{0}$ and $\beta_{1}$ for the average payroll equation are not statistically significant at conventional levels. The Wald exclusion test statistic for this equation is 3.88 , and its probability value is 0.14 .

These results are statistically consistent with the model's prediction that all adjustment of total industry payroll reflects changes in the number of retailers and not their average payroll. However, the estimated magnitude of average payroll's response to the current relative price, the relatively high probability value for that equation's exclusion test, and the one-year delay of establishments' response all suggest the more conservative conclusion that the Food Stores industry responds to relative price movements by changing both the number of stores and their average size. As described in Footnote 2 above, this is exactly the pattern we expect if potential entrants can respond to persistent real relative cost shocks only after one year. It is inconsistent with a model in which sticky retail prices are responsible for persistent deviations from purchasing power parity.

Finally, note that the autoregressive parameter estimates indicate that both the number of establishments in a county and their average payrolls are persistent time series. The diagonal elements of $\Lambda$ are both large and positive, while its off-diagonal elements are much smaller and statistically insignificant. The other three industries' estimated autoregressive coefficients are very similar to Food Stores.

To better gauge the economic significance of our estimates for Food Stores, we have plotted the responses of $\ln N_{i t}$ and $\ln W_{i t}$ to a persistent innovation in the current relative price. Figure 2 displays these impulse-response functions over a ten-year horizon. Its top panel plots the response of $\ln N_{i t}$, whereas its bottom panel plots the response of $\ln W_{i t}$. For 
both panels, we assumed that $\ln r_{t}$ follows an $\mathrm{AR}(1)$ process

$$
\ln r_{t}=\kappa+0.87 \ln r_{t-1}+v_{t}
$$

where $v_{t}$ is an i.i.d. disturbance term with mean zero and standard deviation 0.037. With these parameter values, the unconditional standard deviation and first autocorrelation of $\ln r_{t}$ equal their sample values. Each panel's solid line plots the response to a one standard deviation positive impulse to $v_{t}$. The dashed lines plot the upper and lower limits of pointwise 95\% confidence intervals for the impulse response function. These confidence intervals reflect sampling uncertainty regarding the model parameters $\Lambda$ and $\beta$, but they do not reflect uncertainty about the true process for $\ln r_{t}$.

Both variables' impulse response functions display considerable persistence. Figure 2 demonstrates the positive effect of a real exchange rate appreciation on the number of establishments operating in Food Stores. Although this effect is not instantaneous, the Wald test of the hypothesis that this impulse response function equals zero both contemporaneously and one year out has a probability value of $0.077 .{ }^{11}$ The impact of a real exchange rate shock on establishments after five years is approximately .7\%. The test that this impulse response function equals zero for all horizons between two and five years has a probability value of 0.103. For average payroll, the instantaneous impact of the shock is about six tenths of one percent, and its impact after five years is around one percent. The impact of the shock on average payroll after one year is positive and statistically significant. The relevant pointwise confidence intervals for the shock's impact at other horizons all include zero. The test that this impulse response function equals zero for horizons between two and five years has a probability value of 0.291 . In sum, over short horizons of a year or less, it appears that the food store industry responds to a shock to its relative price by changing both its average establishment size and the number of establishments. Over longer horizons, the industry accommodates the shock primarily through net entry.

\footnotetext{
${ }^{11}$ We have conducted these tests for all of the impulse-response functions reported in this paper. These test statistics' values are nearly identical to the corresponding statistics in Table 6 , discussed below.
} 


\section{B Other Industries}

Table 6 reports the estimates of $\beta$ and the exclusion tests for all four of the industries we consider, and Figures 3, 4, and 5 graph their impulse response functions. Just as with Food Stores, the responses in these figures are to a persistent real exchange rate shock from a first-order autoregression parameterized to match the reported statistics in Table 4.

The results for Gasoline Service Stations are very similar to those for Food Stores. In particular, the lagged gasoline-based real exchange rate has a positive and statistically significant coefficient while the coefficient on the current relative price is insignificant. Thus, in this industry the number of establishments responds to real exchange-rate shocks after one year. The Wald test rejects the exclusion restriction for establishments at the $5 \%$ level, but not for average payroll. However, the Wald test statistic for the average payroll equation is not very small; so it is premature to conclude that Gasoline Service Stations' average payroll does not respond to real exchange rate shocks. The impulse-response functions for Gasoline Service Stations reflect the delayed response of net entry to the exchange rate shock. In the year of the shock, average payroll rises more than $1 \%$, while the number of establishments falls very slightly. Thereafter, the increase in average payroll persists as the number of establishments rises. After five years, the number of establishments has increased by approximately $2 \%$.

Of the four industries we consider, Eating Places most resembles the stark behavior of our model with immediate entry. Although neither of the coefficients on the real exchange rate are individually significant in the establishments equation, the Wald test's probability value is relatively low, 0.025. The corresponding Wald test statistic for the average payroll equation is very small. The impulse response functions for Eating Places show that fluctuations in the number of establishments play a central role in the responses to real exchange rate disturbances. The contemporaneous responses of establishments and average payroll to the exchange rate shock are nearly equal. After impact, average payroll quickly returns to its pre-shock value, while the number of establishments persists at its higher level. 
Our final industry is Drinking Places. These estimates are quite different from those of the other industries. The standard errors of the estimated coefficients for the establishments equation are much larger than in the other industries we consider. Furthermore, the coefficient on the contemporaneous real exchange rate in the average payroll equation is .775 . This is by far the largest absolute value of any of our estimated coefficients, and it is statistically significant at the $5 \%$ level. The Wald exclusion test also indicates that real exchange rate fluctuations have a strong impact on the average payroll of Drinking Places in border counties. The response of establishments to the shock is not statistically significant at any horizon. In contrast, Drinking Places' average payroll rises nearly $4 \%$ in the period of the shock, and it slowly falls back to its pre-shock level.

\section{Alternative Sensitivity Measures}

Because the baseline sensitivity measure's construction required a choice of $\lambda \theta$ in (17), we wish to examine the implications of using alternative sensitivity measures. We have also calibrated values of $\lambda$ and $\theta$ based on Ford's (1992) survey of Canadian consumers' crossborder shopping habits. The calibrated values of $\lambda$ and $\theta$ are 0.71 and 25 , so that $\lambda \theta=17.75$. Although this is much larger than our baseline choice of $\lambda \theta$, the empirical results we obtain using it are nearly identical to our baseline results. We do not report them.

Table 7 reports the estimates obtained from two other measures of $s_{i}$. The table's upper panel reports the result of using the fraction of total one-day trips across the border at county $i$ that are made by Canadians:

$$
s_{i}=\frac{T_{i C}}{T_{i U}+T_{i C}} .
$$

This trips-based sensitivity measure requires no choice of $\lambda$ or $\theta$, but it replaces $S_{i U}$ with a noisy proxy, $T_{i U}$. The table's lower panel reports the results of setting $s_{i}$ equal to the fraction of local residents who are Canadian:

$$
s_{i}=\frac{S_{i C}}{S_{i U}+S_{i C}},
$$


where $S_{i C}$ is measured using Canada's 1991 census as the number of Canadians living within fifty miles of county $i$ 's central point, as defined by the U.S. Census. As we noted above in Section II, this population-based measure takes no account of the potential difficulties in travelling between these Canadians homes and county $i$.

In spite of these potential shortcomings, the results from these two alternative measures of $s_{i}$ are very similar to each other and to our baseline measure. The point estimates from using the trips-based sensitivity measure are nearly identical to our baseline estimates, and the pattern of inference is also similar to that based on the test statistics in Table 6 . The point estimates from using the population-based sensitivity measure are also very similar to those in Table 6, but the pattern of inference changes more. Overall, these alternative sensitivity measures do not substantially alter the conclusion that establishments in Food Stores, Gasoline Service Stations, and Eating Places, respond within one year to real exchange rate disturbances. ${ }^{12}$

\section{OLS Estimation}

To gain a sense of how our results depend on our GMM estimation procedure, Table 8 reports results from estimating a version of our model using ordinary least squares. These estimates are only consistent as the number of time periods in the sample becomes large for a fixed number of counties, an assumption that poorly characterizes our sample of 256 counties over 20 years. Nevertheless, the estimated coefficients on the real exchange rate are very similar to those reported in Table 6. The estimated standard errors are comparable to those from the GMM estimation, and inference based on their exclusion tests is similar to that using the GMM based tests. However, the exclusion test's probability value rises to 0.138 for the coefficients in Eating Places' establishments equation while it falls to 0.038

\footnotetext{
${ }^{12}$ We have also estimated our model using a sensitivity measure that simply equals one if the county is on the U.S.-Canada border and equals zero otherwise. The results from this estimation are also similar to those from the baseline estimation.
} 
for those in Gasoline Service Stations' average payroll equation. It appears that our results manifest themselves even in a simple OLS regression.

\section{Related Literature}

This paper's analysis of the effects of border residents' arbitrage opportunities and their effects on retail trade industries is related to the literature in international economics which focuses on the degree of goods' market segmentation. Engel and Rogers (1996) examine relative consumer-level prices between U.S. and Canadian cities and conclude that U.S. and Canadian markets are segmented to a greater extent than can be explained by distance, formal trade restrictions, or sticky nominal prices. Our findings that movements in real exchange rates have real effects on U.S. industries located near the border strongly suggest that these price differences extend right up to the U.S.-Canada border and so characterize nearly identical goods that are sold only a short distance apart. These observations reinforce Engel and Roger's conclusion that U.S. and Canadian goods markets are not well integrated and suggests that international segmentation characterizes other markets such as input markets for labor, wholesale goods, and distribution networks.

Our results are also related to the branch of international macroeconomics which focuses on the puzzle of persistent deviations from PPP and the related observation that consumer prices are not very responsive to nominal exchange rate movements. Obstfeld and Rogoff (2000) examine environments in which nominal prices are fixed in producers' currencies (producer currency pricing) while Betts and Devereux (2000) and Chari, Kehoe, and McGrattan (2000b) present models in which sticky nominal prices are denominated in the currency of consumers (local currency pricing). Devereux and Engel (2000) and Engel (2001) demonstrate that these two classes of models have very different implications for the degree of optimal exchange rate flexibility. Our finding that the expenditure-shifting effects

of exchange rates impact the number of operating establishments in Food Stores, Gasoline 
Service Stations, and Eating Places is inconsistent with the view that stickiness in retailers' nominal prices is a central cause of persistent deviations from PPP. Our results do not directly support the assumption of producer currency pricing, but they do eliminate one otherwise promising source of sticky local currency pricing, retailers. This places responsibility for any nominal price stickiness upstream to either wholesalers, manufacturers, or as in the case of gasoline in the early 1980's, regulators.

Much of the theory of industrial organization assumes that entry responds to persistent shocks only in the long run, so that incumbent producers can temporarily earn economic profits following a favorable aggregate demand or cost shock. Baumol, Panzar, and Willig (1982) show that the opposite assumption of very rapid entry with no sunk costs implies that incumbents never earn positive profits and that price always equals average cost. In spite of this theoretical importance, little is known about the speed with which entry can take place following a demand shock. Only in Drinking Places, where alcohol licensing restrictions might present a barrier to entry, does the real exchange rate affect industry activity without changing the number of establishments. In the other three industries we consider, either potential entrants, potential exiters, or both must respond relatively rapidly to demand shocks. In our model economy and its extension discussed in Footnote 1 that incorporates sunk costs of entry and long-lived producers, all fluctuations in the number of producers reflect the decisions of potential entrants rather than exiting incumbents. This is a very robust theoretical result that only depends on the cost of entry being invariant to the number of entrants and their identities. ${ }^{13}$ Thus, our results strongly suggest that potential entrants can affect their decisions shortly after demand shocks.

\footnotetext{
${ }^{13}$ Campbell and Fisher (1996) present a perfectly competitive industry dynamics model with idiosyncratic producer risk, sunk costs of entry, and endogenous exit. In that model, demand shocks only contemporaneously impact the number of entrants.
} 


\section{Conclusion}

Blinder (1993) asserts that the various microeconomic explanations for individual producers' nominal rigidities are intrinsically untestable because they only generate the single prediction of infrequent price adjustment. Rather than examining the implications of these theories, this paper examines their common prerequisite of a stable industry structure over the short run. For three of the four retail trade industries we examine, the data favors a model in which potential producers' entry decisions respond relatively quickly to the real and nominal disturbances underlying fluctuations in the real exchange rate. The massive, ongoing, and cyclically sensitive restructuring of employment in the manufacturing sector documented by Davis, Haltiwanger, and Schuh (1996) suggests that this critique of sticky price models may be applicable far beyond the four retail trade industries we consider. For this reason, we believe that a more general examination of the comovement of net entry with real exchange rates is a promising avenue for future research into the source of nominal price rigidities.

Our results cast doubt on theories of sluggish individual price adjustment based on producers' costs of changing nominal prices, but the observations that individual producers change their prices infrequently and that their price changes are not highly correlated, made for example by Carlton (1986) and Lach and Tsiddon (1996), remain. The observation of infrequent price adjustment does not immediately imply that producers face nominal rigidities. For example, Eden (1994) demonstrates that infrequent discrete jumps in nominal prices are also consistent with an uncertain and sequential trading (UST) model in which sellers are indifferent among a large range of real prices. In that environment, one optimal pricing policy is to change a nominal price only when inflationary pressures causes the corresponding real price to move out of that range. Eden (2001) argues that observed price adjustment patterns in Lach and Tsiddon's (1996) data are inconsistent with an environment based on nominal rigidities but are consistent with a simple UST model. Our results reinforce this conclusion and suggest that the informational frictions underpinning the UST model may be quite important for the retail trade industries we consider. 


\section{References}

Baumol, William J., John C. Panzar, and Robert D. Willig. (1982) Contestable Markets and the Theory of Industry Structure. New York, Harcourt Brace Jovanovich.

Betts, Caroline and Michael Devereux. (2000) Exchange Rate Dynamics in a Model of Pricing-to-Market. Journal of International Economics 50, 215-244.

Blinder, Alan S. (1993) Why Are Prices Sticky? Preliminary Results from an Interview Study, in Optimal Pricing, Inflation, and the Cost of Price Adjustment, Eytan Sheshinski and Yoram Weiss, eds., MIT Press, Cambridge, MA.

Blundell, Richard and Stephen Bond. (1998) Initial Conditions and Moment Restrictions in Dynamic Panel Data Models. Journal of Econometrics, 87(1), 115-143.

Campbell, Jeffrey R. and Jonas D.M. Fisher. (1996) Aggregate Employment Fluctuations with Microeconomic Asymmetries. NBER Working Paper 5767.

Carlton, Dennis W. (1986) The Rigidity of Prices. American Economic Review, 76(4), $637-658$.

Chari, V.V., Patrick J. Kehoe, and Ellen R. McGrattan. (2000a) Sticky Price Models of the Business Cycle: Can the Contract Multiplier Solve the Persistence Problem? Econometrica, 68(5), 1151-1179.

Chari, V.V., Patrick J. Kehoe, and Ellen R. McGrattan. (2000b) Can Sticky Price Models Generate Volatile and Persistent Real Exchange Rates? Federal Reserve Bank of Minneapolis Research Department Staff Report 277.

Christiano, Lawrence J., Martin Eichenbaum, and Charles Evans. (2001) Nominal Rigidities and the Dynamic Effects of a Shock to Monetary Policy. NBER Working Paper 8403.

Davis, Steven J., John C. Haltiwanger, and Scott Schuh. (1996) Job Creation and Destruction, MIT Press, Cambridge, MA. 
Devereux, Michael B. and Charles Engel. (2000) Monetary Policy in the Open Economy Revisited: Price Setting and Exchange Rate Flexibility. NBER Working Paper 7665.

Eden, Benjamin. (1994) The Adjustment of Prices to Monetary Shocks when Trading is Uncertain and Sequential. Journal of Political Economy, 102(3), 493-509.

Eden, Benjamin. (2001) Inflation and Price Adjustment: An Analysis of Micro Data. Review of Economic Dynamics, 4(3), 607-636.

Engel, Charles and John Rogers. (1996) How Wide is the Border? American Economic Review, 86(5), 1112-1125.

Engel, Charles. (2001) The Responsiveness of Consumer Prices to Exchange Rates and the Implications for Exchange-Rate Policy: A Survey of a few Recent New Open-Economy Macro Models. Working Paper, University of Wisconsin.

Ford, Theresa. (1992) International Outshopping Along the Canada-United States Border: The Case of Western New York. Canada-United States Trade Center Occasional Paper No. 12, State University of New York at Buffalo

Foster, Lucia, John Haltiwanger, and C.J. Krizan. (2001) The Link Between Aggregate and Micro Productivity Growth: Evidence from Retail Trade. Working Paper, University of Maryland.

Lach, Saul and Daniel Tsiddon. (1996) Staggering and Synchronization in Price-Setting: Evidence from Multiproduct Firms. American Economic Review, 86(5), 1175-1196.

MacDonald, James M. and Daniel Aaronson. (2000) How Do Retail Prices React to Minimum Wage Increases? Federal Reserve Bank of Chicago Working Paper 00-20.

Obstfeld, Maurice and Kenneth Rogoff. (2000) New Directions for Stochastic Open Economy Models. Journal of International Economics, 50(1), 117-153. 
Table 1: Quartiles from Sample Counties of Average Establishment Counts

\begin{tabular}{l|cccc} 
Industry & Counties $^{(\mathrm{i})}$ & First Quartile $^{(\mathrm{ii})}$ & Median $^{(\mathrm{ii})}$ & Third Quartile $^{(\mathrm{ii})}$ \\
\hline Food Stores & 256 & 26.7 & 45.0 & 93.3 \\
& & & & \\
$\begin{array}{l}\text { Gasoline Service } \\
\text { Stations }\end{array}$ & 256 & 18.9 & 28.8 & 51.2 \\
Eating Places & 245 & 39.1 & 74.2 & 145.7 \\
& & & & \\
Drinking Places & 235 & 11.8 & 18.6 & 38.5
\end{tabular}

Notes: (i) Refers to the number of counties included in the estimation sample for each industry. (ii) For each included county, the average number of establishments serving each industry between 1977 and 1996 was calculated. 'First Quartile', 'Median', and 'Third Quartile' refer to the quartiles of that statistic across all sample counties for that industry. See the text for further details.

Table 2: Median Within-County Standard Deviations ${ }^{(i)}$

\begin{tabular}{l|cc} 
Industry & Establishments & Average Payroll \\
\hline Food Stores & 0.11 & 0.14 \\
$\begin{array}{l}\text { Gasoline Service } \\
\text { Stations }\end{array}$ & 0.13 & 0.16 \\
Eating Places & 0.09 & 0.10 \\
Drinking Places & 0.17 & 0.22
\end{tabular}

Note: (i) For each industry, each of the variables was first logged and regressed against a set of time dummies. The sample standard deviations of the residuals from that regression was tabulated for each county. The values reported in the table are the medians, across counties, of these statistics. See the text for further details. 
Table 3: Consumer Price Index Sources for Relative Price Series

\begin{tabular}{l|ll} 
Industry & U.S. CPI ${ }^{(\mathrm{i})}$ & Canadian $\mathrm{CPI}^{(\mathrm{i})}$ \\
\hline Food Stores & Food at Home & Food Purchased from Stores \\
$\begin{array}{l}\text { Gasoline Service } \\
\text { Stations }\end{array}$ & Gasoline & Gasoline \\
Eating Places & Food Away from Home & Food Purchased from Restaurants \\
Drinking Places & $\begin{array}{l}\text { Alcoholic Beverages } \\
\text { Away from Home }\end{array}$ & Served Alcoholic Beverages
\end{tabular}

Note: (i) For each industry, the column headed U.S. CPI reports the name of the consumer price index series used in constructing the relative price, and the column headed Canadian CPI reports the name of the analogous Canadian series. See the text for further details.

Table 4: Summary Statistics for Relative Price Series ${ }^{(i)}$

\begin{tabular}{l|ccc} 
Industry & Standard Deviation & First Autocorrelation & $\begin{array}{c}\text { Correlation with Aggregate } \\
\text { Real Exchange Rate }\end{array}$ \\
\hline Food Stores & 0.075 & 0.87 & 0.63 \\
& & & 0.47 \\
$\begin{array}{l}\text { Gasoline Service } \\
\text { Stations }\end{array}$ & 0.214 & 0.88 & 0.93 \\
Eating Places & 0.070 & 0.75 & 0.92
\end{tabular}

Notes: (i) The first two columns report the standard deviation and first autocorrelation of the relative price series used for the corresponding industry over the sample period 19771996. The final column gives the contemporaneous correlation between the relative price series and the relative price of "all goods less energy". (ii) Sample period for the relative price series for Drinking Places begins in 1979. See the text for further details. 
Table 5: Estimates for SIC 54, Food Stores ${ }^{(i),(i i)}$

\begin{tabular}{lrr} 
& \multicolumn{2}{c}{ Dependent Variable } \\
\cline { 2 - 3 } & Establishments & Average Payroll \\
\cline { 2 - 2 } $\begin{array}{l}\text { Lagged Establishments, } \\
\ln N_{i t-1}\end{array}$ & $\begin{array}{r}0.788^{* * *} \\
(0.025)\end{array}$ & -0.027 \\
Lagged Average Payroll, & & $(0.053)$ \\
$\ln W_{i t-1}$ & 0.026 & $0.689^{* * *}$ \\
& $(0.018)$ & $(0.051)$ \\
Current Real Exchange Rate, & & \\
$s_{i} \times \ln r_{t}$ & -0.071 & 0.152 \\
& $(0.060)$ & $(0.128)$ \\
Lagged Real Exchange Rate, & & 0.041 \\
$s_{i} \times \ln r_{t-1}$ & $0.151^{* *}$ & $(0.152)$ \\
Exclusion Test for & $(0.075)$ & 3.88 \\
Real Exchange Rate & & $(0.143)$ \\
& 4.98 &
\end{tabular}

Notes: (i) Heteroskedasticity-consistent standard errors appear in parentheses below each coefficient estimate. (ii) The superscripts $*, * *$, and $* * *$ indicate that the estimate is statistically different from zero at the $10 \%, 5 \%$, and $1 \%$ levels. (iii) The Wald exclusion tests are asymptotically distributed as $\chi^{2}$ random variables with 2 degrees of freedom. Probability values from this distribution appear below each test statistic. See the text for further details. 
Table 6: Baseline Estimation Results ${ }^{(i)(i i)}$

\begin{tabular}{l|ccc|ccc|}
\cline { 2 - 7 } Industry & \multicolumn{3}{|c|}{ Establishments } & \multicolumn{3}{c|}{ Average Payroll } \\
Food Stores & $s_{i} \times \ln r_{t}$ & $s_{i} \times \ln r_{t-1}$ & $\chi^{2} \mathrm{Test}^{(\mathrm{iii})}$ & $s_{i} \times \ln r_{t}$ & $s_{i} \times \ln r_{t-1}$ & $\chi^{2}$ Test $^{(\mathrm{iii})}$ \\
& -0.071 & $0.151^{* *}$ & 4.98 & 0.152 & 0.041 & 3.88 \\
& $(0.060)$ & $(0.075)$ & $(0.083)$ & $(0.128)$ & $(0.152)$ & $(0.143)$ \\
Gasoline Service & -0.044 & $0.128^{* *}$ & 9.07 & 0.118 & 0.045 & 2.29 \\
Stations & $(0.040)$ & $(0.051)$ & $(0.011)$ & $(0.089)$ & $(0.061)$ & $(0.318)$ \\
& & & & & \\
Eating Places & 0.108 & 0.038 & 7.35 & 0.093 & -0.079 & 0.86 \\
& $(0.091)$ & $(0.071)$ & $(0.025)$ & $(0.109)$ & $(0.094)$ & $(0.651)$ \\
Drinking Places & 0.148 & -0.092 & 1.19 & $0.775^{* *}$ & -0.337 & 6.77 \\
& $(0.144)$ & $(0.147)$ & $(0.550)$ & $(0.336)$ & $(0.273)$ & $(0.034)$
\end{tabular}

Notes: (i) Heteroskedasticity-consistent standard errors appear in parentheses below each coefficient estimate. (ii) The superscript $* *$ indicates that the estimate is statistically different from zero at the $5 \%$ level. (iii) Asymptotically, this test statistic has a $\chi^{2}$ distribution with 2 degrees of freedom. Probability values from this distribution appear in parentheses below each test statistic. See the text for further details. 
Table 7: Estimation Results using Alternative Sensitivity Measures ${ }^{(i)(i i)}$

\begin{tabular}{|c|c|c|c|c|c|c|}
\hline \multirow[b]{2}{*}{ Industry } & \multicolumn{5}{|c|}{$s_{i}=$ Canadian Trips $/$ Total Trips } & \\
\hline & $s_{i} \times \ln r_{t}$ & $\begin{array}{c}\text { Establishmen } \\
s_{i} \times \ln r_{t-1}\end{array}$ & $\chi^{2}$ Test $^{(i i i)}$ & \multicolumn{3}{|c|}{$s_{i} \times \ln r_{t} \quad s_{i} \times \ln r_{t-1} \quad \chi^{2}$ Test $^{(\mathrm{iii})}$} \\
\hline Food Stores & $\begin{array}{l}-0.083 \\
(0.070)\end{array}$ & $\begin{array}{l}0.159^{*} \\
(0.083)\end{array}$ & $\begin{array}{c}4.25 \\
(0.119)\end{array}$ & $\begin{array}{c}0.199 \\
(0.145)\end{array}$ & $\begin{array}{c}0.013 \\
(0.167)\end{array}$ & $\begin{array}{c}5.35 \\
(0.069)\end{array}$ \\
\hline $\begin{array}{l}\text { Gasoline Service } \\
\text { Stations }\end{array}$ & $\begin{array}{l}-0.045 \\
(0.042)\end{array}$ & $\begin{array}{l}0.132^{* *} \\
(0.055)\end{array}$ & $\begin{array}{c}7.28 \\
(0.024)\end{array}$ & $\begin{array}{c}0.115 \\
(0.095)\end{array}$ & $\begin{array}{l}-0.058 \\
(0.061)\end{array}$ & $\begin{array}{c}1.47 \\
(0.480)\end{array}$ \\
\hline Eating Places & $\begin{array}{c}0.106 \\
(0.129)\end{array}$ & $\begin{array}{c}0.048 \\
(0.092)\end{array}$ & $\begin{array}{c}6.96 \\
(0.031)\end{array}$ & $\begin{array}{c}0.077 \\
(0.127)\end{array}$ & $\begin{array}{l}-0.091 \\
(0.103)\end{array}$ & $\begin{array}{c}0.78 \\
(0.678)\end{array}$ \\
\hline Drinking Places & $\begin{array}{c}0.189 \\
(0.194)\end{array}$ & $\begin{array}{l}-0.146 \\
(0.197)\end{array}$ & $\begin{array}{c}1.02 \\
(0.600)\end{array}$ & $\begin{array}{c}0.983^{* * *} \\
(0.353)\end{array}$ & $\begin{array}{l}-0.444 \\
(0.286)\end{array}$ & $\begin{array}{c}9.21 \\
(0.010)\end{array}$ \\
\hline \multicolumn{7}{|c|}{$s_{i}=$ Canadian Population $/$ Total Population } \\
\hline Industry & $s_{i} \times \ln r_{t}$ & $\begin{array}{c}\text { Establishmen } \\
s_{i} \times \ln r_{t-1} \\
\end{array}$ & $\chi^{2}$ Test $^{(i i i)}$ & $s_{i} \times \ln r_{t}$ & $\begin{array}{l}\text { verage Pay } \\
s_{i} \times \ln r_{t-1} \\
\end{array}$ & $\chi^{2}$ Test $^{(i i i)}$ \\
\hline Food Stores & $\begin{array}{c}-0.120^{*} \\
(0.069)\end{array}$ & $\begin{array}{l}0.206^{* *} \\
(0.087)\end{array}$ & $\begin{array}{c}6.44 \\
(0.040)\end{array}$ & $\begin{array}{c}0.112 \\
(0.116)\end{array}$ & $\begin{array}{l}-0.104 \\
(0.136)\end{array}$ & $\begin{array}{c}0.93 \\
(0.627)\end{array}$ \\
\hline $\begin{array}{l}\text { Gasoline Service } \\
\text { Stations }\end{array}$ & $\begin{array}{c}0.012 \\
(0.034)\end{array}$ & $\begin{array}{c}0.033 \\
(0.049)\end{array}$ & $\begin{array}{c}3.97 \\
(0.137)\end{array}$ & $\begin{array}{l}0.128^{* *} \\
(0.061)\end{array}$ & $\begin{array}{l}-0.027 \\
(0.053)\end{array}$ & $\begin{array}{c}8.30 \\
(0.016)\end{array}$ \\
\hline Eating Places & $\begin{array}{c}0.064 \\
(0.078)\end{array}$ & $\begin{array}{c}0.028 \\
(0.063)\end{array}$ & $\begin{array}{c}8.24 \\
(0.016)\end{array}$ & $\begin{array}{l}-0.060 \\
(0.076)\end{array}$ & $\begin{array}{c}0.083 \\
(0.090)\end{array}$ & $\begin{array}{c}0.85 \\
(0.653)\end{array}$ \\
\hline Drinking Places & $\begin{array}{l}-0.025 \\
(0.101)\end{array}$ & $\begin{array}{c}0.102 \\
(0.102)\end{array}$ & $\begin{array}{c}2.30 \\
(0.316)\end{array}$ & $\begin{array}{c}0.338 \\
(0.227)\end{array}$ & $\begin{array}{l}-0.215 \\
(0.202)\end{array}$ & $\begin{array}{c}2.37 \\
(0.306)\end{array}$ \\
\hline
\end{tabular}

Notes: (i) Heteroskedasticity-consistent standard errors appear in parentheses below each coefficient estimate. (ii) The superscripts $*, * *$ and $* * *$ indicate that the estimate is statistically different from zero at the 10\%, 5\%, and 1\% levels. (iii) Asymptotically, this test statistic has a $\chi^{2}$ distribution with 2 degrees of freedom. Probability values from this distribution appear in parentheses below each test statistic. See the text for further details. 
Table 8: OLS Estimation Results ${ }^{(i)(i i)}$

\begin{tabular}{l|ccc|ccc|}
\cline { 2 - 7 } Industry & \multicolumn{3}{|c|}{ Establishments } & \multicolumn{3}{c|}{ Average Payroll } \\
Food Stores & $s_{i} \times \ln r_{t}$ & $s_{i} \times \ln r_{t-1}$ & $\chi^{2} \mathrm{Test}^{(\mathrm{iii})}$ & $s_{i} \times \ln r_{t}$ & $s_{i} \times \ln r_{t-1}$ & $\chi^{2} \mathrm{Test}^{(\mathrm{iii})}$ \\
& -0.107 & 0.176 & 2.62 & 0.140 & 0.063 & 3.78 \\
& $(0.094)$ & $(0.112)$ & $(0.270)$ & $(0.124)$ & $(0.170)$ & $(0.152)$ \\
Gasoline Service & -0.048 & $0.135^{* *}$ & 14.32 & 0.113 & -0.023 & 6.54 \\
Stations & $(0.057)$ & $(0.057)$ & $(0.000)$ & $(0.075)$ & $(0.074)$ & $(0.038)$ \\
& & & & & 0.030 \\
Eating Places & 0.119 & 0.006 & 3.96 & 0.111 & 0.080 & 0.72 \\
& $(0.082)$ & $(0.092)$ & $(0.138)$ & $(0.133)$ & $(0.111)$ & $(0.698)$ \\
Drinking Places & 0.153 & -0.082 & 1.00 & $0.818^{* * *}$ & -0.299 & 15.96 \\
& $(0.172)$ & $(0.176)$ & $(0.60)$ & $(0.296)$ & $(0.290)$ & $(0.000)$
\end{tabular}

Notes: (i) Heteroskedasticity-consistent standard errors appear in parentheses below each coefficient estimate. (ii) The superscripts $* *$ and $* * *$ indicate that the estimate is statistically different from zero at the $5 \%$ and $1 \%$ levels. (iii) This test statistic has an asymptotic $\chi^{2}$ distribution with 2 degrees of freedom as $T \rightarrow \infty$. Probability values from this distribution appear in parentheses below each test statistic. See the text for further details. 
Figure 1: The Real Exchange Rate and Cross-Border Shopping

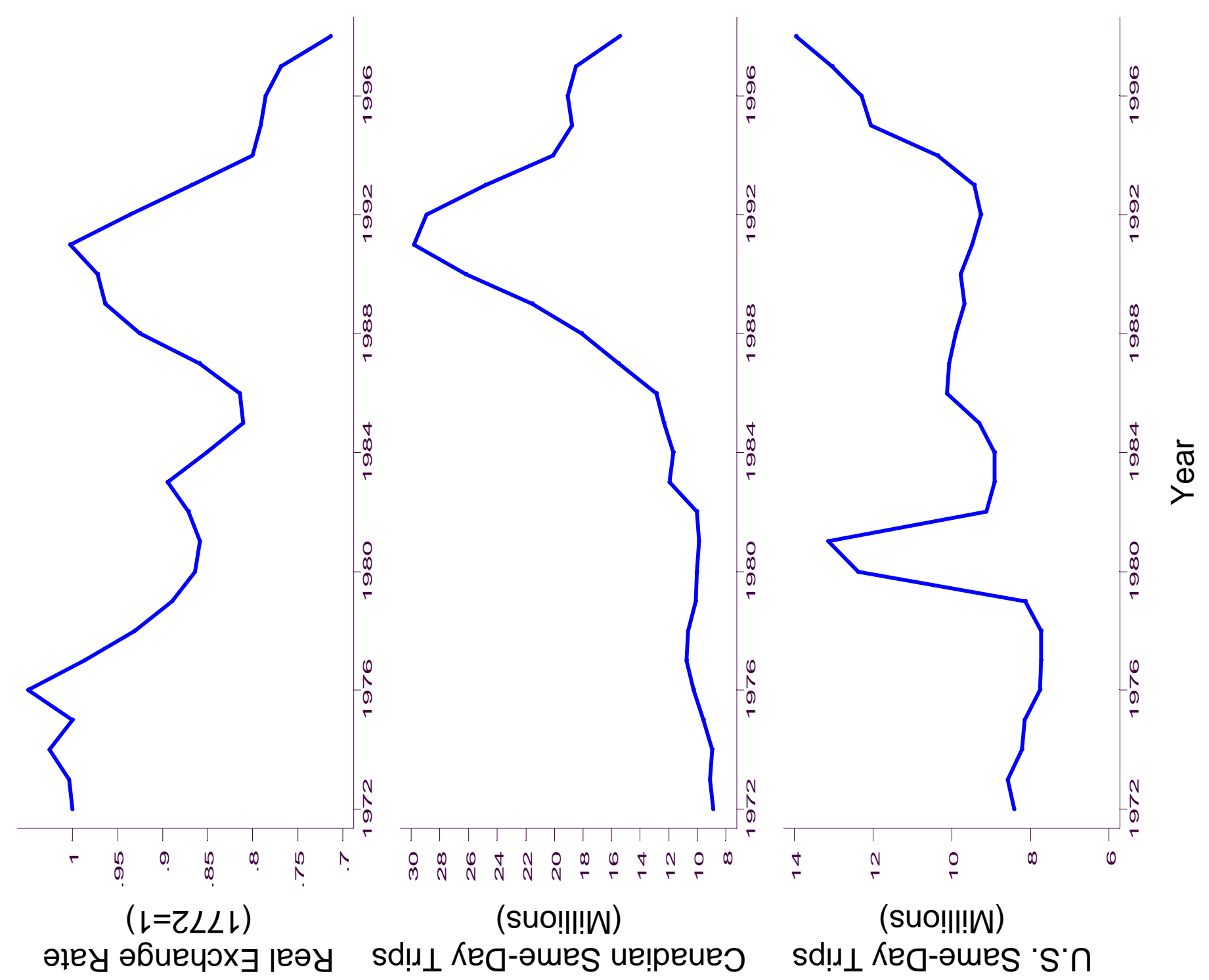


Figure 2: Impulse-Response Functions for SIC 54, Food Stores

Establishments
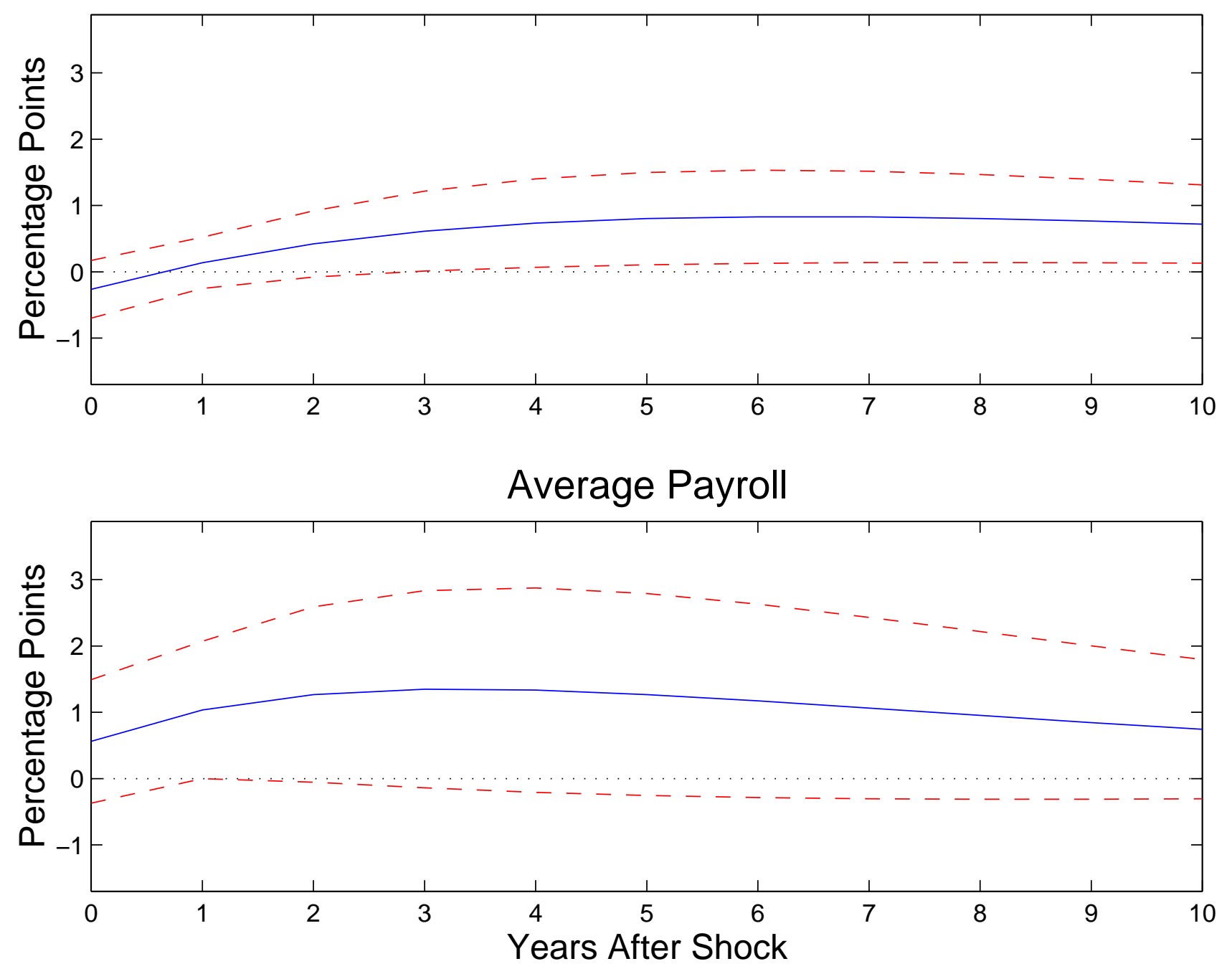
Figure 3: Impulse-Response Functions for SIC 554, Gasoline Service Stations

Establishments

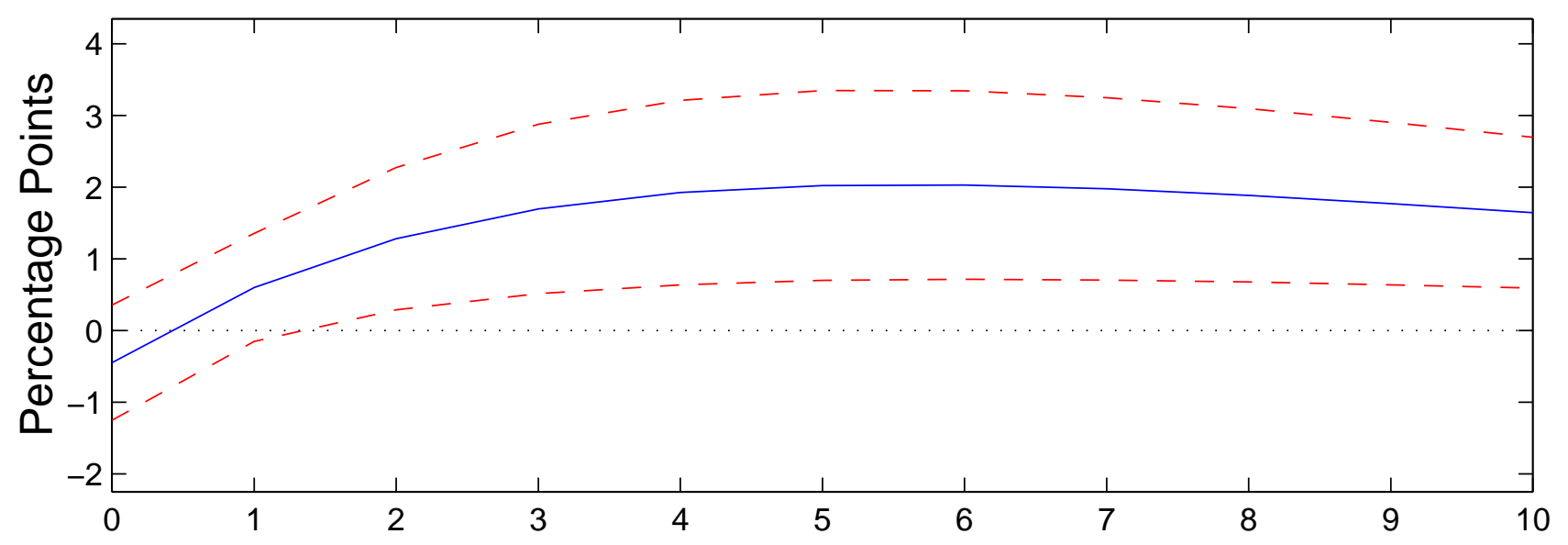

Average Payroll

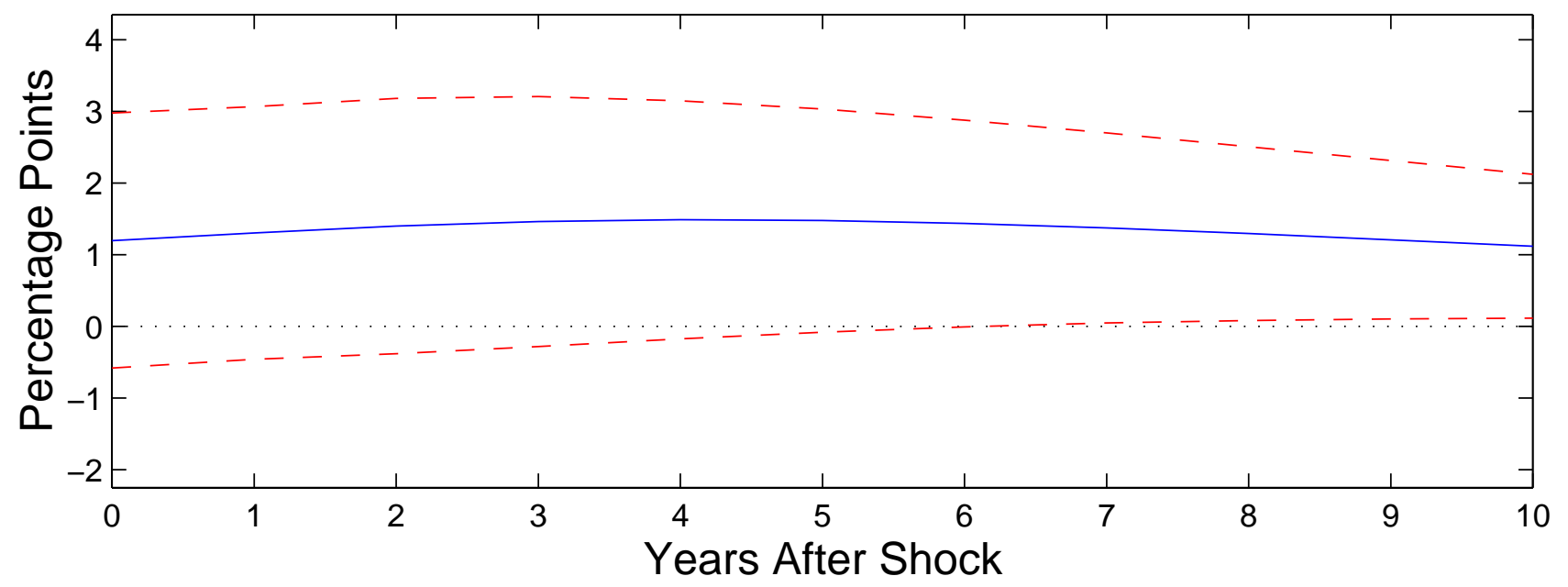


Figure 4: Impulse-Response Functions for SIC 5812, Eating Places

Establishments

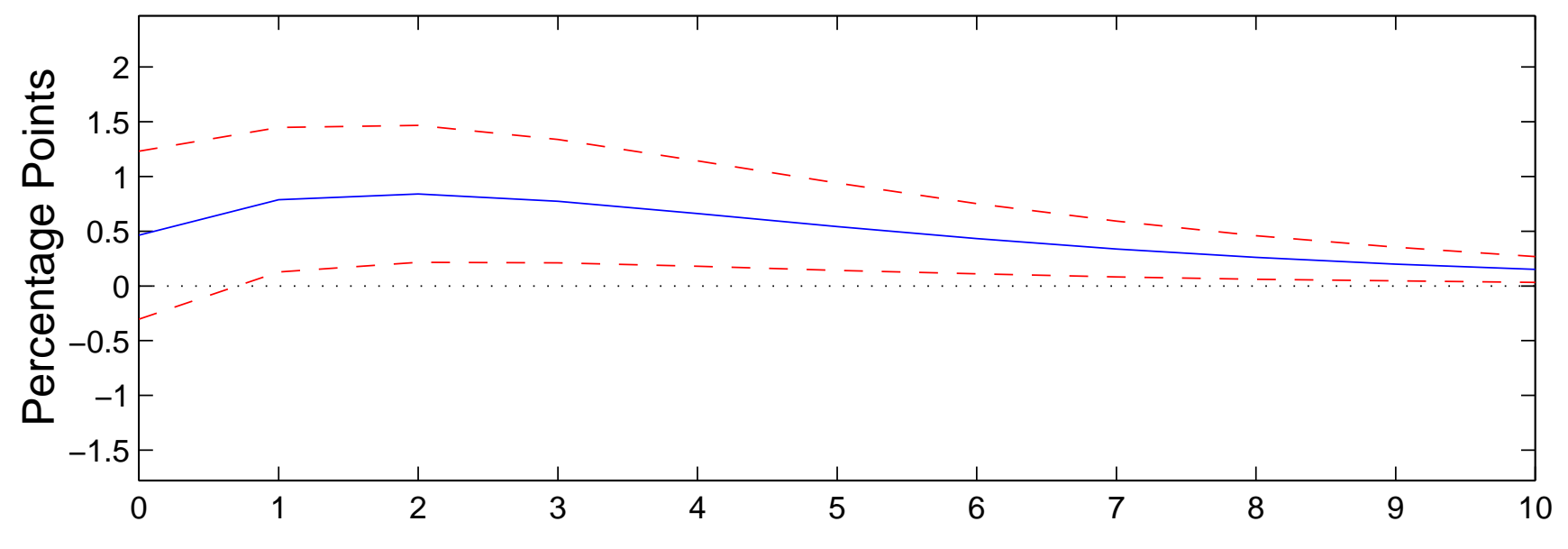

Average Payroll

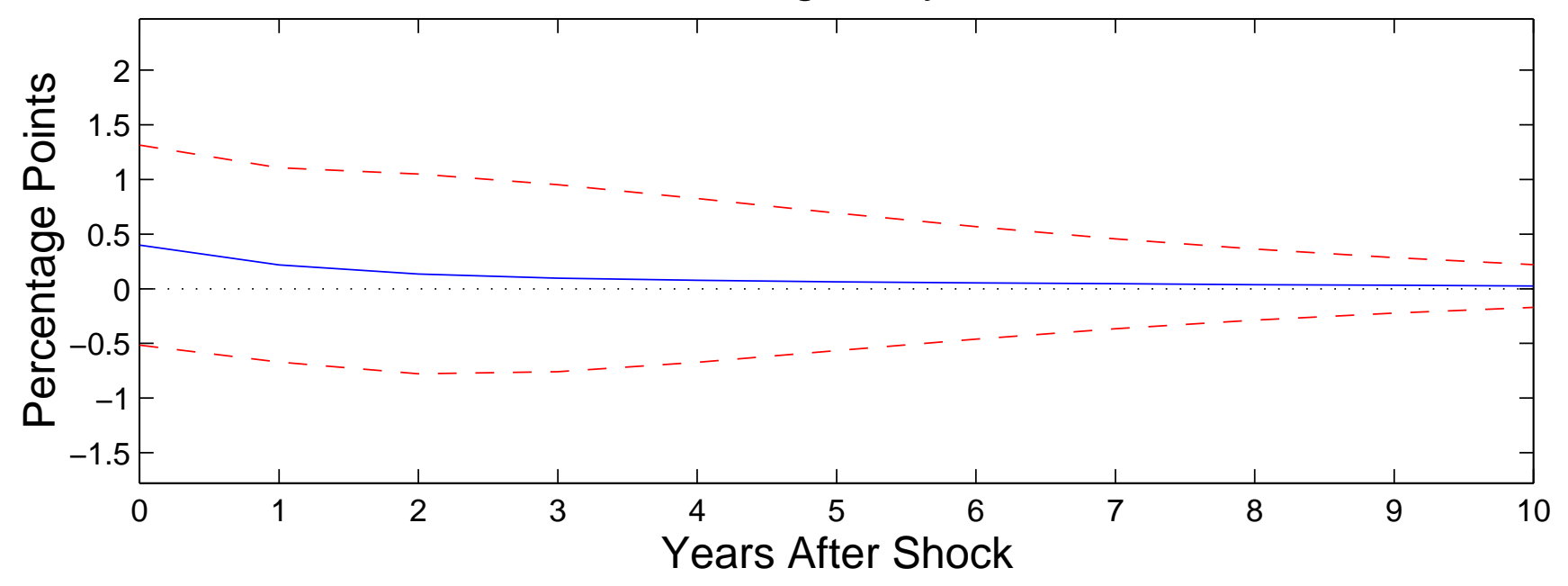


Figure 5: Impulse-Response Functions for SIC 5813, Drinking Places

Establishments

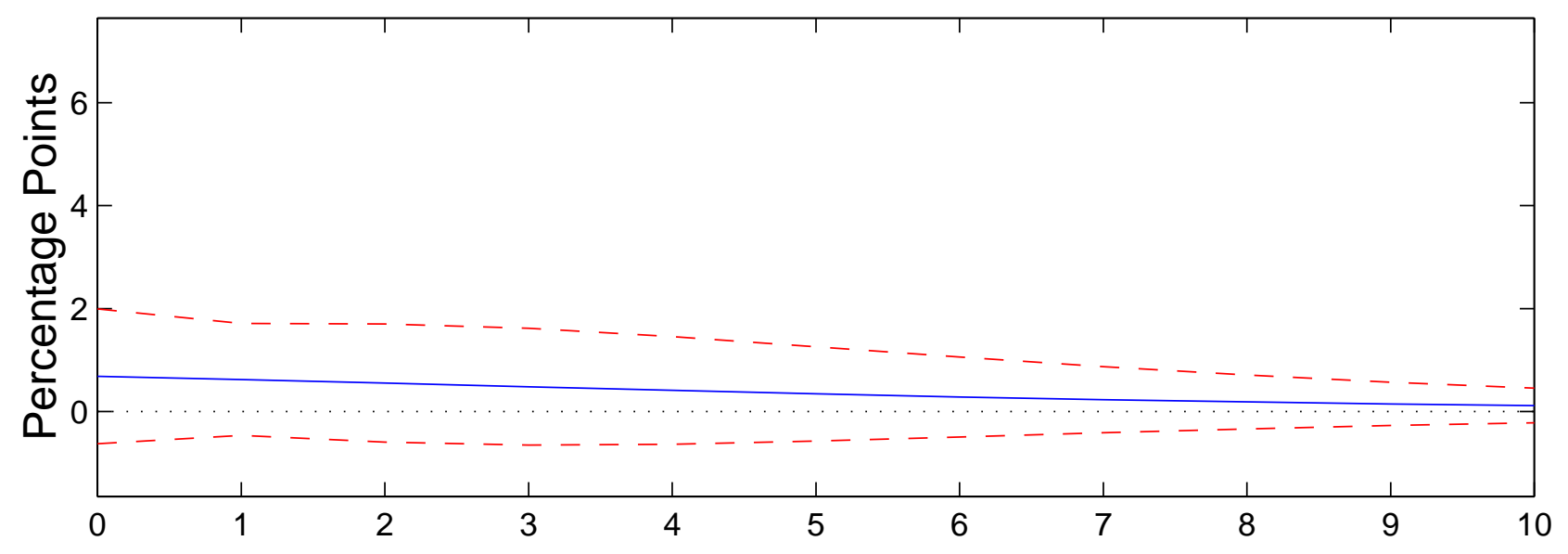

Average Payroll

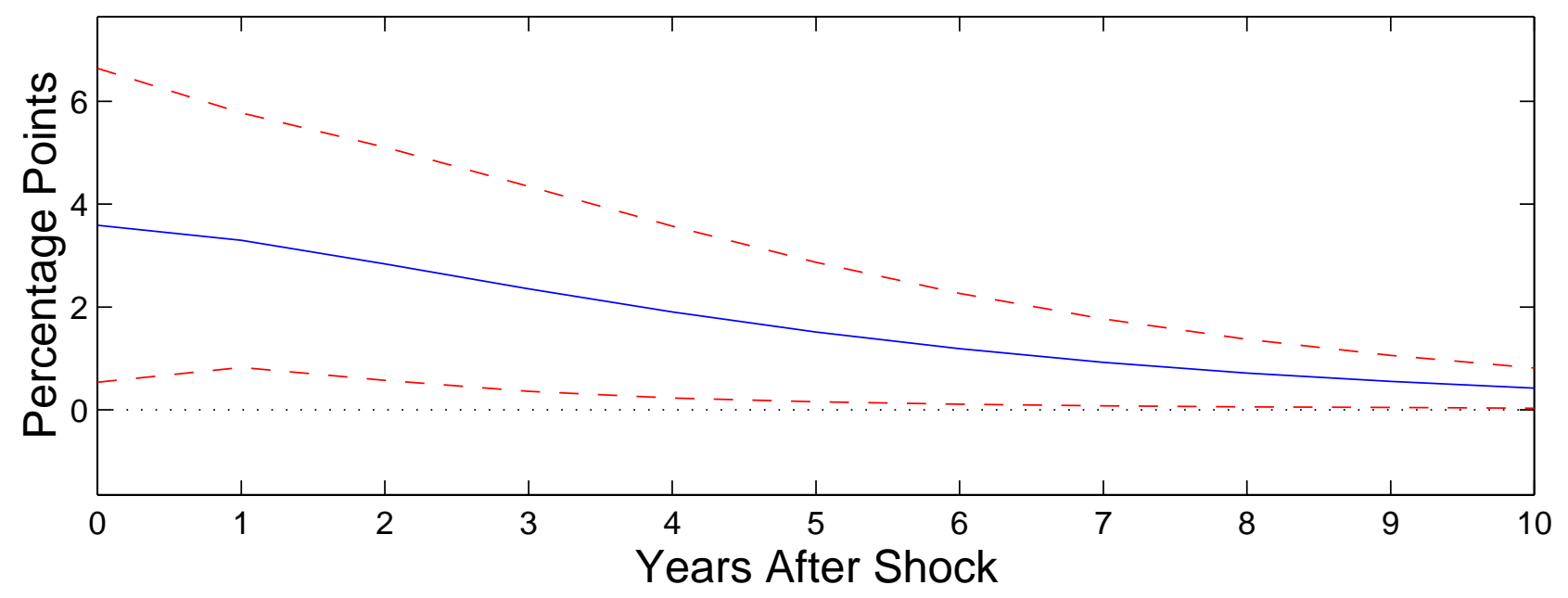

